\title{
El gozo intelectual spinoziano
}

\section{Spinozian Intellectual Joy}

\author{
Pilar Benito Olalla ${ }^{1}$ \\ IES Diego Porcelos (España)
}

Recibido: 26-04-18

Aprobado: 14-07-18

\section{Resumen}

Este artículo se centra en el gozo intelectual spinoziano. Después de un breve repaso de un libro de Jorge Wagensberg sobre la experiencia del gozo intelectual, aludo al fenómeno contrario: el pensamiento sombrío y el pesimismo. Después, remarco la defensa de Spinoza del gozo del conocimiento y su poder contra la tristeza y el pesimismo. Finalmente, analizo el peculiar gozo intelectual en Spinoza (el tercer género de conocimiento) y conecto este gozo con la experiencia de eternidad y su expresión a través de categorías espaciales.

Palabras-clave: gozo intelectual, eternidad, categorías espaciales, conocimiento.

\begin{abstract}
This article is focussed on the intellectual joy in Spinoza. After a brief review of Jorge Wagensberg's book about the experience of the intellectual joy, I allude to the opposite phenomenon: the dismal thought and pessimism. Then, I remark the Spinoza's defence of the knowledge's joy and his power against the sadness and the pessimism. Finally, I analyse the peculiar intellectual joy in Spinoza (the third kind of knowledge) and I connect this joy with the experience of eternity and his expression through spatial categories.
\end{abstract}

Key-words: Intellectual Joy, Eternity, Spatial Categories, Knowledge.

\footnotetext{
${ }^{1}$ Doctora en Filosofía por la UNED, es profesora en enseñanza secundaria. Entre sus publicaciones relacionadas con Spinoza se encuentran las siguientes: "Algunos destellos de la luz de Spinoza: de una metáfora de Dilthey al relámpago en Romain Rolland”, Endoxa, 29 (2012); Baruch Spinoza. Una nueva ética para la liberación humana, Madrid, Biblioteca Nueva, 2015; "La potencia humana del amor transformada en el amor intelectual de Dios" en María Luisa de la Cámara y Julián Carvajal (eds.): Spinoza y la antropología en la Modernidad, Hildesheim, Georg Olms Verlag, 2017. El presente artículo es fruto de mi participación en el congreso "Spinoza: nuevos caminos", organizado por el Seminario Spinoza (a quienes doy las gracias), y que tuvo lugar en la Universidad de Castilla-La Mancha en Cuenca en marzo de 2017.
} 


\section{Introducción}

Todas las familias felices se parecen; las desdichadas lo son cada una a su modo². Tólstoi, Anna Karénina

El placer —es más profundo aún que el sufrimiento: El dolor dice: ;Pasa!

Mas todo placer quiere eternidad,- iQuiere profunda, profunda eternidad! $!^{3}$

Nietzsche, Asi habló Zaratustra

¿Quizás la alegría es una y común a todos los hombres como el logos de Heráclito, y la tristeza es tan múltiple como cada ego particular?

¿Quizás el sufrimiento está atado al tiempo, y la felicidad no solo aspira a ser eterna, sino que ya lo es en cada experiencia plena?

El afán por conocer era el afecto más fuerte en Spinoza. En ese proceso cognoscitivo él mismo experimentaba una gran alegría. Y cuanto más se acrecentaba su comprensión de las ideas adecuadas y de la conexión entre ellas, más aumentaba su contento de sí y su potencia, y más su deseo de comunicar a los otros lo aprehendido. Incluso el mayor gozo provenía de poder llegar a intuir $-\mathrm{y}$ de nuevo comunicar- con la sabiduría que emana del prisma de la eternidad; una eternidad experimentada y sentida con tal rotundidad que no cabían fisuras, y que certificaba a la vez el éxito del método geométrico. ¿O no? Es evidente que Spinoza sintió muchas veces el gozo intelectual. Su obra es una prueba viva de ello y también sus testimonios así lo corroboran. Sin embargo, no sabemos si consiguió alcanzar la anhelada y amorosa ciencia intuitiva con la que culmina la obra de su vida. Preguntas en tropel vienen a la mente: ¿En qué consiste esa escurridiza alegría que se produce al conocer y se prolonga y consuma cuando se traslada lo conocido a los demás? ¿Es el mismo ese contento en Spinoza que en otros disfrutadores del conocimiento? ¿O es acaso similar también al de los lectores que conectan con sus escritos? ¿Quizás contagioso, adictivo?

Sirvan ahora unos breves apuntes para acercarse con sigilo a esa experiencia afectiva e intelectiva antes de que se nos escape, acelerada y evanescente, entre palabras.

\footnotetext{
${ }^{2}$ Lev N. Tólstoi, Anna Karénina, Barcelona, Alba Editorial, 2017, p. 23.

${ }^{3}$ Friedrich Nietzsche, Así habló Zaratustra, Madrid, Alianza, 1980, p. 429.
} 


\section{El gozo intelectual}

La más alta filosofía, la metafísica, se ha hermanado tradicionalmente con lo mejor de las actividades humanas. Aristóteles insistía con ahínco desde su labor pedagógica en el Liceo que "todos los hombres desean por naturaleza saber" $y$ " "que es más sabiduría la que se elige por sí misma y por saber, que la que se busca a causa de sus resultados, y que la destinada a mandar es más sabiduría que la subordinada"'5. Y además - prosigue el Estagirita- es la ciencia mejor y más libre y su búsqueda nos acerca a los dioses. Y a esa ciencia han de conducirnos con método firme todas nuestras indagaciones.

Sin embargo, y pesar de las excelencias prometidas en el camino y de los logros parciales conseguidos en tan noble y natural tarea, pocos son los que a ella dedican la duración de su vida. La rareza se explica por las dificultades siempre presentes en cada conatus por conocer, por la fuerza de las causas externas, por el esfuerzo exigente y concentrado que implica tal dedicación y los peligros de extravío, por las tendencias de cada temperamento o los avatares educativos que no atinaron a dinamizar la primera ficha de dominó que iniciara un proceso imparable, o por otras mil disculpas que el propio sujeto interponga por no dedicarse a lo más excelso, difícil y raro, sí, a aquello a lo que nos retaba Spinoza. Pero, sobre todo y fundamentalmente, por la ausencia de un método de conocimiento, eficaz y adecuado. El orden genera comprensión y generar orden es disminuir la entropía de la ignorancia y aumentar la potencia del conatus; también la belleza y perfección del mundo a la luz de nuestros ojos bien enfocados.

Cuando ese método ordenado y ordenador nos permite avanzar en el espacio de nuestra visión cognoscitiva, esa expansión es gozosa, alegre, buena, hasta corporalmente bienhechora, vivaz y radiante. Las caprichosas etimologías acuden en nuestra ayuda. Ivonne Bordelois, discípula de Chomsky y, lo que es más importante, poetisa, nos ilumina con los significados tan corpóreos que las palabras albergaban en sus orígenes:

...beatus significa feliz, dichoso, rico, floreciente, magnífico, abundante, fecundo, fértil; pero también beato, santo, bondadoso, venerable, digno de canonización. De una misma raíz deu- (potencia para hacer, dinamismo...) vienen bueno, bello y beato (feliz). (Bello es un diminutivo de bueno, bonulus, como bonito en español es un diminutivo de bueno $)^{6}$.

Y más adelante continúa Bordelois:

\footnotetext{
${ }^{4}$ Aristóteles, Metafisica, libro I, 980a, Madrid, Gredos, 1982, p. 2.

5 Ibídem, libro I, 982 14 ss, p. 11.

${ }^{6}$ Ivonne Bordelois, Etimología de las pasiones, Buenos Aires, Libros del zorzal, 2017, p. 148.
} 
Desde el punto de vista etimológico, lo más llamativo de nuestro término alegría es su relación con las nociones de agilidad, velocidad y vivacidad que encierra su antecedente, el latín clásico alacritas...Alacer significa, en latín: alegre, pronto, presto, ágil, vivo, ligero, gozoso.

La alacritas latina, al parecer, acentuaba una imagen más dinámica que propiamente emocional ${ }^{7}$.

Y en esta misma línea, para explicar la conexión originaria entre palabras y actitudes corporales, esta autora recurre al gran filólogo H. Kurath ${ }^{8}$ para ejemplificar el caso de la alegría:

Demuestra Kurath así que en las lenguas indoeuropeas las palabras que denotan 'moverse con vivacidad, saltar, etc.' son las que proveen el asiento para las denominaciones de los afectos relacionados con la alegría...

En otros casos, patentes en el sánscrito o en las antiguas lenguas germánicas, la fortaleza, el vigor, la hinchazón, el crecimiento se relacionan con la alegría -y también, es cierto, con la arrogancia- ${ }^{9}$.

Así vemos que la alegría va unida a la bondad, también a la fecundidad, al vigor, y al dinamismo, la agilidad y la velocidad, incluso a la sensación física del brillo (por ejemplo, la expresión "radiante de alegría") ${ }^{10}$. Por ello, la expansión cognoscitiva que a su vez nos expande el pecho es saludable, nos integra, centraliza la identidad y genera fortalecido el impulso transmisor hacia los otros.

Ya tenemos algunas pistas sensitivas y emocionales, también lingüísticas (etimológicas), del disfrute sentido cuando seguimos la línea conativa del conocimiento. Ahora bien, ¿en qué consiste ese proceso?, ¿es posible establecer un esquema conceptual para explicarlo? Jorge Wagensberg, físico y reputado divulgador científico, dedicó un libro a desentrañarlo, titulado precisamente $E l$ gozo intelectual.

Como buen científico y como mandan los cánones, Wagensberg comienza con la definición: "llamo 'gozo intelectual' al que ocurre en el momento exacto de una nueva comprensión o de una nueva intuición" ${ }^{11}$. A continuación explica lo que entiende por 'comprensión' (“caer en la mínima expresión de lo máximo compartido"12) e 'intuición' ("un roce entre dos estados de la mente: un roce

\footnotetext{
${ }^{7}$ Ibidem, p. 150.

${ }^{8}$ Hans Kurath fue un filólogo de origen austriaco afincado en Norteamérica que se centró en el estudio de la lingüística histórica y la evolución social del inglés en los Estados Unidos. Bordelois hace referencia a su obra titulada The Semantic Sources of the Words for Emotions in Sanskrit, Greek, Latin and the Germanic Languages (1921).

9 Ibidem, p. 151.

${ }^{10}$ Ibidem, p. 155.

11 Jorge Wagensberg, El gozo intelectual. Teoría y practica sobre la inteligibilidad y la belleza, Barcelona, Tusquets Editores, 2007, p. 23.

12 Ibidem, p. 23.
} 
entre la incertidumbre resuelta y la incertidumbre por resolver"13) para acabar equiparando ambos términos en el sentido de "comprensión súbita o revelada" o "salto" en el conocimiento".

Resulta obvio que ese proceder implica alegría cuando se accede al chispazo del comprender, es más, las dos transiciones - cognitiva en el conocimiento y afectiva en el gozo- ocurren al mismo tiempo, son sincrónicas, y manifiestan un aumento de potencia al estilo spinozista. Por ello, matizo la definición anterior y añado otros dos elementos presentes en tal estado: el gozo intelectual es la alegría inherente al proceso del conocimiento y a sus logros, y la necesidad de compartirlo con los demás. Es cierto que el gozo más pleno ocurre en el instante de la intuición, vivido como una epifanía (es el denominado efecto eureka o la experiencia ; aha! o el insight, que ha estudiado la psicología) ${ }^{15}$, pero también se da durante todo el proceso de búsqueda, en ese caminar a tientas en ocasiones, o encontrase con dificultades o aporías. Pero lo importante es avanzar, experimentar las transiciones de modo consciente, alegrarse por la expansión diría que espacial-del conatus. Y cualquier aparente límite o muro se convierte en reto para un nuevo despliegue colonizador del espacio cognoscitivo, y ese despliegue se vive con regocijo. Insisto en el aspecto transitivo de esta experiencia porque es ahí donde sentimos el contento, además de incidir en su carácter abierto en un doble sentido: por un lado, los logros del conocimiento son siempre parciales y nos urgen a nuevas e incesantes búsquedas, por otro lado, esa alegría individual se desborda de uno mismo y su corriente saludable fluye en la transmisión a los demás, una transmisión que se pretende lo más universal posible. Toda vez que se inicia este dinamismo, resulta imparable y enriquecedor, porque lo descubierto genera nuevos enigmas, y lo compartido y comprendido por otros aporta un aumento en proporción geométrica del propio conocer. Y ahí es donde reside su magia y la calidad específica de este disfrute genuino e incomparable: en las continuas transiciones. Que conste que me estoy refiriendo al conocimiento auténtico, a esa experiencia fuerte, no a los sucedáneos amparados por un pretendido ingenio del lenguaje, el sarcasmo, la crítica feroz, la retórica banal o la actitud negativa de oposición constante sin fundamentar. Aquí solo puede haber disminución de la potencia, y tristeza.

Para ahondar más en los vericuetos del gozo intelectual -aunque lo crucial es sentirlo y comunicarlo-, retornemos a Wagensberg y a su análisis pormenorizado de las tres fases sucesivas, pero no excluyentes, en las que lo divide: el estímulo, la conversación y la comprensión e intuición propiamente

13 Ibidem, p. 24.

${ }^{14}$ Ibídem, pp. 23 y 24.

15 El psicólogo Kart Bühler - perteneciente a la Escuela de Wurzburgo- analizó las fases en la resolución de problemas. De las cuatro fases que estudia (preparación, incubación, iluminación y evaluación), encuadramos el gozo intelectual propiamente en la tercera, la iluminación. En esta fase se produce la vivencia del ;ah!, cuando adviene la solución al problema con total claridad; lo que habitualmente se conoce como inspiración.

Araucaria. Revista Iberoamericana de Filosofia, Politica, Humanidades y Relaciones Internacionales, año $21, \mathrm{n}^{\circ} 41$. Primer semestre de 2019. Pp. 117-138. ISSN 1575-6823 e-ISSN 2340-2199 doi: 10.12795/araucaria.2019.i41.06 
dichas. En la primera fase del estímulo es cuando se decide con determinación, e incluso a veces con urgencia, querer conocer algo. Esta catapulta inicial o apertura perceptiva al mundo es necesaria para dar el empuje y la dirección a ese deseo cognoscitivo. Porque a partir de ahí -y en conjunciones sincrónicasirán emergiendo todos los elementos que apoyarán y nutrirán el proceso: es la segunda fase, la conversación. El conversar -intercambio adecuado y eficaz de preguntas y respuestas- es muy amplio y variado: conversar con la realidad (observar, experimentar, etc.), con los demás (amigos, profesores, discípulos, etc.) y con uno mismo (reflexionar). Las conversaciones permiten avanzar en nuestras pesquisas, ir probando lo descubierto y elegir entre distintas opciones. La última fase, comprensión e intuición, ocurre de modo súbito, y es el lugar exacto de radical soledad y ensimismamiento donde se da el gozo intelectual propiamente dicho, aunque en las dos fases anteriores también se dan gozos mentales. Tal es la importancia de este concepto -según Wagensberg-que puede tomarse como criterio y motor de nuevos conocimientos, de experiencia de autenticidad y honestidad, así como convertirse en pivote de la educación:

El gozo intelectual es el concepto más relevante del conocer. Educar quizá consista sólo en enseñar a gozar, a gozar el estímulo, a gozar la conversación y, sobre todo, a gozar la comprensión. El gozo intelectual es también la señal más fiable con la que se puede orientar el creador de conocimiento. El intelectual es un ciudadano que lo tiene fácil para ser honesto en su trabajo si tal fuera su ilusión. En el mundo de las ideas quizá baste, sencillamente, con atender al gozo intelectual y conducirse de gozo en gozo $^{16}$.

Veremos más adelante cómo se dieron estas fases en la búsqueda filosófica de Spinoza y qué tenía de especial su culminación intuitiva. Pero ahora conviene atender de modo dialéctico, también breve, a la voz de aquellos que no han incidido en esta experiencia de alegría, sino más bien al contrario, en la pesadumbre del pensamiento, uno de los elementos de la infelicidad. Aunque resulte paradójico tratar de ello en este artículo sobre Spinoza y la felicidad, pero así esta quedará mucho más resaltada.

\section{El pensamiento sombrío}

Desde los reflejos en la iconografía del sufriente Heráclito hasta las especulaciones de George Steiner sobre la tristeza del pensar, ha habido toda una serie de autores y obras que resaltan el lado sombrío del esfuerzo por conocer. ¿Cuáles son sus razones? ¿Nos convencen? ¿O acaso aumentan

\footnotetext{
${ }^{16}$ Ibidem, p. 43.
} 
nuestra potencia cuando llegamos a entenderlas bajo un prisma más amplio y transitamos de la tristeza a la alegría? Un libro trinitario y ya mítico que recoge los avatares de este estado anímico sombrío, de manera selectiva por la literatura y el arte fundamentalmente, es Saturno y la melancolía ${ }^{17}$. Del variado tratamiento que hacen sus autores sobre la multifacética melancolía, me interesa rescatar el famoso escrito denominado Problema XXX,1-atribuido en la Antigüedad a Aristóteles, pero seguramente de Teofrasto, y remodelado por la tradición posterior-, en el que se sientan las bases argumentales de la relación entre el hombre de conocimiento, el genio, y la melancolía, unida al humor de la bilis negra. Este texto griego comienza con una pregunta siguiendo la estructura típica de la tradición pedagógica aristotélica y peripatética:

¿Por qué todos los que han sobresalido en la filosofía, la política, la poesía o las artes eran manifiestamente melancólicos, y algunos hasta el punto de padecer ataques causados por la bilis negra, como se dice de Heracles en los [mitos] heroicos? ${ }^{18}$

A continuación se hace un desarrollo exhaustivo y perspicaz de los tipos de melancolía, sus causas y sus efectos, atendiendo a la fisiología. En Platón, este anormal estado se asociaba con los héroes, poseídos por el furor divino doblemente inspirador y destructor. Sin embargo, a raíz de Aristóteles, este concepto mítico se amplía y evoluciona en parte hacia una visión más científica y corporal: la melancolía como estado natural de los hombres sobresalientes, anormales, que han de templar con justeza (eukrasía) la cantidad (ni poca ni mucha) y la temperatura (ni demasiado caliente ni demasiado fría) de su bilis negra constitutiva para conseguir logros intelectuales, y superar los escollos de cierta tendencia patológica inherente a ese carácter. Y aunque en el texto se plantea la distinción entre melancolía natural y enfermedad melancólica con sus funestas consecuencias, también se advierte de que la primera puede transformarse por momentos en la segunda, dada la complejidad pregnante y variable de este estado ${ }^{19}$. Y aquí el propio idioma acude en nuestra ayuda, como cuando decimos que las cosas se tiñen de un manto de melancolía o es ella la que nos invade.

De todas las ricas disquisiciones que ofrece el Problema $X X X, 1$, lo que se ha rescatado en la tradición posterior es esa relación peculiar entre la vida del intelecto y la melancolía; asunto fecundo para la especulación sobre el cual contamos con innumerables estudios hasta la actualidad: desde el clásico de Richard Burton hasta los trabajos de especialistas contemporáneos como Jackie

\footnotetext{
17 Raymond Klibansky, Edwin Panofsky, Fritz Saxl, Saturno y la melancolía, Madrid, Alianza Forma, 2006.

18 Ibidem, p. 42.

19 Ibidem, p. 56.
}

Araucaria. Revista Iberoamericana de Filosofia, Politica, Humanidades y Relaciones Internacionales, año $21, \mathrm{n}^{\circ} 41$. Primer semestre de 2019. Pp. 117-138. ISSN 1575-6823 e-ISSN 2340-2199 doi: 10.12795/araucaria.2019.i41.06 
Pigeaud, Jean Starobinski o Julia Kristeva ${ }^{20}$. Y por recoger alguno más reciente y contestarlo, me voy a detener solo en el librito del ya aludido George Steiner, Diez (posibles) razones para la tristeza del pensamiento ${ }^{21}$. Amparándose en un texto harto citado de Schelling donde se habla del fundamento oscuro de la vida humana y del conocimiento ${ }^{22}$, Steiner despliega su aparato de razones bajo la égida de un sutil escepticismo. Algunas ya manidas, otras muy elaboradas y elegantes, las causas de la tristeza del pensar desfilan ante nosotros: la aparente infinitud del pensamiento en toda su gama de posibilidades no conduce a nada concluyente y definitivo; la concentración y esfuerzo sostenidos que exige el pensar solo son accesibles a muy pocas personas y durante periodos de tiempo breves; el pensar es un acto de íntima privacidad en su forma, a la vez que revela su carácter común y repetitivo en su fondo, puesto que hay muy pocos pensamientos originales en el flujo de la actividad cognitiva de las personas; el pensamiento se enfrenta a una contradicción insoluble entre la búsqueda de la verdad y nuestra precondición ligüística que nos aleja de ella y nos sume en el juego de las ambigüedades, si exceptuamos el coto de las tautologías matemáticas; la actividad del pensar es derrochadora y ruinosa, ya que de todo lo pensado muy poco fructifica en logro del conocimiento; la correlación entre pensamiento y acción es fallida y conduce al vacío y al desengaño; el hecho de no poder dejar de pensar se convierte en una aterradora servidumbre; el pensamiento propio es opaco para los demás e impone una barrera de extrañeza entre los seres humanos; el pensamiento profundo pertenece a unos pocos y no se puede extender a la sociedad, sino que se pierde la mayoría de las veces

\footnotetext{
20 Algunos títulos destacados sobre la melancolía: el clásico y monumental estudio de Robert Burton, Anatomía de la melancolía, Madrid, Alianza, 2015 (Selección de textos a cargo de Alberto Manguel); la reciente edición del Problema XXX, Aristóteles, El hombre de genio y la melancolía, Barcelona, Acantilado, 2016; Marek Bienczyk, Melancolía, Barcelona, Acantilado, 2014; Jean Starobinski, La tinta de la melancolía, Madrid, FCE, 2017; Jackie Pigeaud, La maladie de l'âme: Étude sur la relation de l'âme et du corps dans la tradition médico-philosophique antique, París, Belles Lettres, 2006, y Melancholia: le malaise de l'individu, París, Payot et Rivages, 2008; Julia Kristeva, Sol negro. Depresión y melancolía, Terrados (Girona), Wunderkammer, 2017; Yves Hersant, Mélancolies de l'Antiquité au XXe siècle, París, Bouquins, 2005.

${ }^{21}$ George Steiner, Diez (posibles) razones para la tristeza del pensamiento, Madrid, Siruela, 2007.

22 Ibídem, pp. 9 y 10, cita que hace Steiner de los textos de Schelling, Sobre la esencia de la libertad humana: "Ésta es la tristeza que se adhiere a toda vida mortal, una tristeza que, sin embargo, nunca llega a la realidad, sino que sólo sirve a la perdurable alegría de la superación. De ahí el velo de la pesadumbre, el cual se extiende sobre la naturaleza entera, de ahí la profunda e indestructible melancolía de toda vida"... "Sólo en la personalidad está la vida; y toda personalidad se apoya en un fundamento oscuro, que, no obstante, debe ser también el fundamento del conocimiento". Steiner acorta el primer texto. La cita exacta es ésta: "Esta es la tristeza inherente a toda vida finita, e incluso si hay en Dios una condición al menos relativamente independiente, es también una fuente de tristeza, que, empero, nunca se hace efectiva, sino que solo está al servicio de la eterna alegría de la superación. De ahí el velo de tristeza que se extiende sobre toda la naturaleza, la profunda e inquebrantable melancolía de toda vida". Schelling, Investigaciones filosóficas sobre la esencia de la libertad humana y los objetos con ella relacionados, Barcelona, Anthropos, 2000, p. 263. Respecto al segundo texto, la traducción es muy similar: "Solo en la personalidad hay vida y toda personalidad reposa sobre un fundamento oscuro, que por lo tanto tiene que ser también del conocimiento". Ibídem, p. 297.
} 
al pairo de los avatares históricos; y por último, sentencia Steiner que no ha habido grandes avances en la reflexión sobre las grandes cuestiones (ser, nada, muerte, Dios).

Hasta aquí las razones de Steiner. ¿Qué decimos a esto? El propio Wagensberg ha contestado punto por punto a cada de ellas desde su actitud optimista y confiada en los avances de la ciencia. Sin embargo, ahora quiero contestarlas desde las herramientas (bien nutridas) -y no son pocas- que nos proporciona Spinoza.

El viaje del conocer es difícil, esforzado; empero, es el mejor, el más excelso. Además resulta necesario para superar los embates tristes, la disminución de la potencia; es, por tanto, ineludible en cuanto seres humanos constituidos por el deseo por perseverar en la existencia y en nuestro modo singular, finito, de ser, y capaces de ejercer la racionalidad y cultivar el conocimiento. Se convierte en catalizador balsámico cuando generamos un orden adecuado y más amplio en medio del desorden entrópico y parcial de las ideas inadecuadas. No podemos dejar de pensar, es obvio, pero sí disponemos del conatus para descubrir un método fuerte y aplicarlo -en beneficio de nuestra potencia- a los estados emocionales que nos advienen, a la corriente errabunda de la imaginación y a los efectos de las causas externas que se nos presentan por el camino. La tristeza es una pasión primaria por la cual pasamos (nuestra mente) hacia una menor perfección (E 3P11S ${ }^{23}$ y a una merma en nuestra potencia de obrar, y es directamente mala (E 4P41) ${ }^{24}$. La melancolía es una clase de tristeza, pero referida a mente y cuerpo, cuando el ser humano es afectado por igual, y no cuando unas partes son más afectadas que otras (E $3 \mathrm{P} 11 \mathrm{~S})^{25}$, y por supuesto, también es siempre mala (E 4P42) ${ }^{26}$. Para superar la tristeza y sus formas dolientes derivadas hay que generar más potencia, más actividad, más conocimiento, y de este modo, sentir ese aumento como alegría. Además, desechar la melancolía es una regla de conducta para Spinoza, que indica la disposición de su ánimo (E 4P45S ${ }^{27}$. En ese empeño conativo por la alegría pueden intervenir todos los resortes cognitivos del hombre debidamente encauzados: desde el esfuerzo por imaginar y recordar las cosas que aumentan la potencia de obrar del cuerpo (E 3P12-P13) ${ }^{28}$, o las modalidades generosas del amor, pasando por el conocimiento racional de las ideas adecuadas, hasta

${ }^{23}$ Para citar las proposiciones de la Ética sigo la notación establecida: E de Ética, número que indica la parte de la Ética citada, P de proposición y número de la misma, S de escolio, si ha lugar, incorporando entre paréntesis la referencia a la edición canónica, Spinoza Opera (SO), de sus obras completas. La edición de la Ética que utilizo es la siguiente: Spinoza, Ética demostrada según el orden geométrico, Madrid, Tecnos, 2007. Traducción de Vidal Peña García. Op. cit., p. 213 (SO 2, 149).

${ }^{24}$ Ibidem, p. 331 (SO 2, 241).

${ }^{25}$ Ibídem, p. 213 (SO 2, 149).

${ }^{26}$ Ibidem, pp. 331-332 (SO 2, 241).

27 Ibidem, pp. 335-336 (SO 2, 244).

${ }^{28}$ Ibidem, pp. 214-216 (SO 2, 150).

Araucaria. Revista Iberoamericana de Filosofia, Politica, Humanidades y Relaciones Internacionales, año $21, \mathrm{n}^{\circ} 41$. Primer semestre de 2019. Pp. 117-138. ISSN 1575-6823 e-ISSN 2340-2199 doi: 10.12795/araucaria.2019.i41.06 
desembocar en el supremo género del conocer, la ciencia intuitiva, pivote en realidad de todo el proceso. Spinoza certifica en su correspondencia un ejemplo muy concreto de cómo enfrentarse a la tristeza: 1664, la peste asola Ámsterdam, ha muerto el hijo de uno de sus mejores amigos, Pieter Balling, y así procura consolarlo por carta:

Su última carta, escrita, si no me engaño, el 26 del mes pasado, llegó correctamente a mis manos. Me causó gran tristeza e inquietud, aunque ésta ha disminuido mucho al constatar con qué prudencia y fortaleza de espíritu ha sabido usted despreciar las molestias de la fortuna o, mejor dicho, de la opinión, en el momento en que dirigen contra usted los más duros ataques. No obstante, mi inquietud se acrecienta de día en día, y por eso le ruego y suplico, por nuestra amistad, que no tenga reparo en escribirme largamente ${ }^{29}$.

Spinoza alaba la prudencia (prudentia) y la fortaleza (fortitudo animi) de espíritu de su amigo y enarbola el poder de la amistad como consuelo. Muchas son las fuentes de tristeza y las causas de la melancolía a lo largo de una vida humana. Desde luego que las tendencias temperamentales, los hábitos adquiridos y el aprendizaje que podamos incorporar influirán en nuestra manera de experimentar esos estados. Pero considero que la raíz profunda y común a las diversas formas de la pesadumbre humana (sea cual sea el abanico de negruras que exhiba el monólogo interior del yo) estriba en nuestra condición mortal. Por eso, Spinoza desentraña el origen del problema cuando apuesta por la vida y dice que el sabio en nada piensa menos que en la muerte. ¿Será posible? ¿Optimismo utópico? ¿U ontológico decantado por la propia experiencia vital de Spinoza y que impregna la nuestra cuando seguimos perseverando en la existencia? Este optimismo -si bien atemperado por su concepción ética abierta y lúcida acerca de las transiciones parciales y provisionales que nos conducen desde la tristeza hacia la alegría- contrasta de raíz con las visiones filosóficas que cultivan el pesimismo, y como ejemplo curioso rescato unos textos de Schopenhauer, hermosos por cierto, donde resulta diáfana la postura inicial pre-reflexiva que hace que una persona -filósofa o no- sea tendente a la amargura, aun disfrutando de los dones del intelecto, porque incluso esos dones -siendo el único motivo de consuelo- se convierten en fuente de dolor añadido por la intensidad y el aislamiento concomitantes:

En efecto, del mundo no hay mucho que tomar: la necesidad y el dolor lo llenan, y a aquéllos que han escapado de esos males los acecha el aburrimiento tras cada esquina. Por lo demás, lo gobierna la maldad, y la estupidez tiene siempre la palabra. El destino es cruel y los seres humanos son infelices. En un mundo

${ }^{29}$ Spinoza, Correspondencia, Madrid, Alianza, 1988. Traducción de Atilano Domínguez. Ep. 17, p. 157 (SO 4, 76).

Araucaria. Revista Iberoamericana de Filosofía, Política, Humanidades y Relaciones Internacionales, año $21, \mathrm{n}^{\circ} 41$. Primer semestre de 2019. Pp. 117-138. ISSN 1575-6823 e-ISSN 2340-2199 doi: 10.12795/araucaria.2019.i41.06 
así, aquél que mucho tiene en su interior es comparable a la cálida habitación navideña, rebosante de luz y alegría, en medio de la nieve y el hielo en la noche de diciembre. Así pues, una individualidad excelente, rica y, sobre todo, rebosante de espíritu, inteligencia e ingenio es la mejor lotería del planeta; aun siendo ésta todo lo diferente que quiera ser de la más esplendorosa y atractiva de las suertes ${ }^{30}$.

En contra de todo esto hemos de tener en cuenta, por otra parte, que los grandes dones del espíritu, como consecuencia de una desmesurada actividad nerviosa, producen una extraordinaria receptividad para el dolor en todas sus formas; que, además, el temperamento apasionado que tales dones suelen tener como condición y, a la vez, la mayor viveza y perfección de todas las representaciones que este temperamento lleva aparejadas producen una extrema violencia de los afectos provocada por éstas, siendo así que son muchos más los afectos penosos que los agradables. Finalmente, ocurre también que los dones extraordinarios del espíritu alejan a su propietario del resto de los hombres y de sus afanes, [pues cuantas más cosas posee en sí mismo, muchas menos encuentra en ellos] y cientos de cosas en las que aquellos encuentran gran satisfacción, a él le resultan insípidas e incomestibles. Por eso quizá tenga también aquí validez la ley universal de la compensación; en efecto, incluso se ha afirmado demasiado a menudo que el hombre de espíritu limitado es, en definitiva, el más dichoso, aunque ciertamente nadie le envidie ese dicha ${ }^{31}$.

En estos textos de tintes gracianescos, todo ello es cierto en determinados aspectos y todos los tópicos melancólicos están dichos, sin embargo algo resuena en nosotros cuando oímos estas palabras y nos rebelamos ante tanta soledad y arrogancia del yo, porque todo en nuestro ser desea la alegría, la acción, la potencia, a pesar de, en medio de y con cualquier tipo de sufrimiento, y también deseamos compartir la fortaleza con los demás. Descubrirlo e intentar vivirlo así, sin rendición -aunque heridos- mientras duramos, es fuente de conocimiento gozoso, y la culminación de ese gozo intelectual spinoziano tiene su peculiar sello de identidad.

\section{El peculiar y paradigmático gozo intelectual spinoziano}

¿Cómo era el gozo intelectual spinoziano? ¿Qué tenía de peculiar y qué de común respeto a otros? ¿Podemos aplicar las tres fases generales analizadas por Wagensberg.: estímulo, conversación e intuición?

Conocemos un punto de inflexión importante en la búsqueda filosófica de Spinoza. Se trata del conocido texto del Tratado de la reforma del entendimiento (TIE), donde según su testimonio se enfrenta a una crisis existencial peligrosa

${ }^{30}$ Arthur Schopenhauer, Aforismos sobre el arte de saber vivir, Madrid, Valdemar, 2012, pp. 66-67.

31 Ibidem, pp. 81-82.

Araucaria. Revista Iberoamericana de Filosofia, Politica, Humanidades y Relaciones Internacionales, año $21, \mathrm{n}^{\circ} 41$. Primer semestre de 2019. Pp. 117-138. ISSN 1575-6823 e-ISSN 2340-2199 doi: 10.12795/araucaria.2019.i41.06 
(escribe la obra después de su salida del judaísmo, punta del iceberg de la verdadera ruptura que se estaba gestando en él desde hacía tiempo); y ante ese peligro, anhela un bien estable, verdadero, que fuera comunicable y que -dice Spinoza- "me hiciera gozar eternamente de una alegría continua y suprema" ("continua ac summa in aeternum fruerer laetitia") ${ }^{32}$ :

Con mi asidua meditación llegué a comprender que, si lograra entregarme plenamente a la reflexión, dejaría males ciertos por un bien cierto. Yo veía, en efecto, que me encontraba ante el máximo peligro, por lo que me sentía forzado a buscar con todas mis fuerzas un remedio, aunque fuera inseguro: lo mismo que el enfermo, que padece una enfermedad mortal, cuando prevé la muerte segura, si no se emplea un remedio, se ve forzado a buscarlo con todas sus fuerzas, aunque sea inseguro, precisamente porque en él reside toda su esperanza. Ahora bien, todas aquellas cosas que persigue el vulgo, no sólo no nos proporcionan ningún remedio para conservar nuestro ser, sino que incluso lo impiden y con frecuencia causan la muerte de quienes las poseen y siempre causan la de aquellos que son poseídos por ellas ${ }^{33}$.

He aquí la plasmación del estímulo inicial que desatará todo el proceso de búsqueda. Y también aquí aparece la segunda fase, la conversación; en este caso, la conversación reflexiva consigo mismo: esa meditación asidua que le permitiría centrarse en el objetivo buscado. Incluso también él nos refiere un éxito, al menos parcial, en esa tarea y con ese método, y con ello, también su gozo:

Sólo veía una cosa: que, mientras mi mente se entregaba a esos pensamientos, se mantenía alejada de dichos afectos y pensaba seriamente en la nueva tarea. Esto me proporcionó un gran consuelo, puesto que comprobaba que esos males no eran de tal índole que resistieran a todo remedio. Y aun cuando, al comienzo, esos intervalos eran raros y de muy escasa duración, a medida que fui descubriendo el verdadero bien, se hicieron más frecuentes y más largos ${ }^{34}$.

Y añade más adelante el autor que quiere comunicar y universalizar ese descubrimiento y esa necesidad de curar el entendimiento y alcanzar el verdadero bien:

.... a mi felicidad pertenece contribuir a que otros muchos entiendan lo mismo que yo, a fin de que su entendimiento y su deseo concuerden totalmente con mi entendimiento y con mi deseo...Es necesario, además, formar una sociedad, tal

32 Spinoza, Tratado de la reforma del entendimiento. Principios de filosofia de Descartes. Pensamientos metafísicos, Madrid, Alianza, 1988. Traducción de Atilano Domínguez. TIE 1, p. 75 (SO 2, 5).

33 Ibídem, TIE 7, pp. 77-78 (SO 2, 6-7).

34 Ibídem, TIE 11, pp. 78-79 (SO 2, 7-8). 
como cabría desear, a fin de que el mayor número posible de individuos alcance dicha naturaleza con la máxima facilidad y seguridad ${ }^{35}$.

Por tanto, en este episodio aparecen con claridad las tres fases aludidas. Y ello viene a confirmar que la experiencia de Spinoza sobre el deleite del conocimiento es similar a la de todos aquellos que la han disfrutado. ¿Pero qué hay de peculiar en ella? Es obvio que elementos específicos como su propio carácter, los avatares de su corta vida, las relaciones tan importantes para su estabilidad con su círculo de amigos, la época en que vivió, otorgan un sabor singular a esa alegría, a ese contento de sí (E 3, def afectos, $n^{\circ} 25$; E 3, P30S). Sin embargo, la búsqueda de Spinoza no pretendía el logro en un campo acotado del saber humano, como puede ser el caso de los avances en las diversas ramas científicas, sino que su radiación de fondo tenía que ver con la empresa más ambiciosa, quizá la más importante a la que podemos aspirar: la felicidad (beatitudo) entendida como liberación en el transcurso de la propia vida y la lucha contra la tristeza y sus derivados. Y a ella y con ahínco dedica su obra magna, la Ética. Tan importante es la experiencia de felicidad para Spinoza que incluso algún autor como Michel Henry ${ }^{36}$ defendió en su momento la hipótesis de que el origen de la búsqueda filosófica spinoziana fue encontrar la felicidad, y que esta finalidad última brotó de una experiencia subjetiva, prerreflexiva y no de un a priori racional y sistemático; incluso llega a afirmar Henry que esta experiencia fuerte prevaleció siempre, como lo probaría el libro V de la Ética, y convertiría todas sus teorías en condiciones de la misma felicidad, generando de esta manera una gran fecundidad cognoscitiva, fruto de esa interacción entre experiencia y sistema, a la vez que produciría también algunas de las contradicciones más sonoras de su filosofía. En palabras de Henry: “¿Por qué Spinoza, buscando la felicidad, hizo una filosofía?" ${ }^{37}$. Puesto que constituye un asunto tan importante para el autor holandés y para todos los seres humanos, lo que ahora nos importa es abordar las siguientes cuestiones sobre la felicidad: ¿En qué consiste la felicidad o beatitud?, ¿es alcanzable?, ¿de qué manera?

Tanto del conocimiento racional como de la ciencia intuitiva puede brotar el gozo, sin embargo es el amor intelectual de Dios, cúspide del tercer género de conocimiento, el que nos proporciona una felicidad con mayúsculas, sin apartar nunca la vía intermedia racional que nos ofrecen la firmeza y la generosidad, y que el autor explica ampliamente en el Libro Cuarto de su Ética, como nos recuerda en la recapitulación final de la Parte Quinta (E 5P41) ${ }^{38}$. La felicidad

\footnotetext{
${ }^{35}$ Ibidem, TIE 14, p. 80 (SO 2, 8-9).

${ }^{36}$ Michel Henry, La felicidad de Spinoza, Buenos Aires, Ediciones La Cebra, 2008 (ed. original: 2004). Esta obra es una memoria o disertación de graduación que elaboró en su juventud entre 1942 y 1943 .

37 Ibidem, p. 35.

38 Spinoza, Ética, op. cit., p. 414 (SO 2, 306).
}

Araucaria. Revista Iberoamericana de Filosofia, Politica, Humanidades y Relaciones Internacionales, año $21, \mathrm{n}^{\circ} 41$. Primer semestre de 2019. Pp. 117-138. ISSN 1575-6823 e-ISSN 2340-2199 doi: 10.12795/araucaria.2019.i41.06 
así concebida es el signo manifiesto de ese estado en que nuestro conocimiento afectivo alcanza una mayor extensión, nuestra mente y nuestro cuerpo activos son capaces de muchas cosas, es decir, somos potentes o virtuosos, y sentimos y experimentamos la propia potencia de la substancia infinita en nosotros. Por tanto, lo que caracteriza de modo peculiar el gozo intelectual spinoziano y lo convierte en paradigmático es que alberga las tres dimensiones fundamentales para la realidad humana: la afectividad (amor), la razón (intelectual) y el infinito (substancia infinita o Dios). Pero sobre todo y especialmente, es la experiencia de eternidad que impregna ese amor intelectual la que marca la diferencia. En una sustanciosa carta a Lodowijk Meyer (la carta 12, denominada "sobre la naturaleza del infinito") y en plena decantación de su filosofía, Spinoza se explica precisamente para aclarar a su círculo de amigos y su editor en este caso acerca de la distinción entre los modos y la substancia, y entre duración y eternidad, e identifica esta última con la substancia infinita y el gozo también infinito de existir, de ser.

De donde se desprende claramente que nosotros concebimos la existencia de la substancia como totalmente diversa de la existencia de los modos. De aquí se deriva la diferencia entre la eternidad y la duración. Pues por la duración sólo podemos explicar la existencia de los modos, mientras que la existencia de la substancia se explica por la fruición infinita de existir o, forzando el latín, de $\operatorname{ser}^{39}$.

Apenas una apreciación sobre el texto, que podrían ser muchas más, dada su condensación expresiva tan propia de Spinoza. Este forzar el latín (invita latinate) por parte del filósofo holandés ha sido percibido por diversos estudiosos como André Tosel (que lo denomina “operación del sive"), Warren Montag (que nos habla del torquere, o retorcer), o Guadalupe González que recoge esta impronta interpretativa cuando descubre una "lexicografía subversiva" en Spinoza con un claro uso estratégico de disidencia política ${ }^{40}$. Aunque desde otra singular perspectiva, el teórico del lenguaje Henri Meschonnic también ha destacado este uso forzado e intencionado de la lengua latina que incluso la acerca al hebreo ${ }^{41}$.

39 Spinoza, Correspondencia, op. cit., Ep. 12, p. 131 (SO 4, 54-55).

${ }^{40}$ Guadalupe González en su introducción a la edición de la obra de Spinoza, Compendio de gramática de la lengua hebrea, Madrid, Trotta, 2005, pp. 9-54. González cita los siguientes libros: André Tosel, Spinoza ou le crépuscule de la servitude, Aubier, París, 1984; Warren Montag, Bodies, masses, power. Spinoza and his Contemporaries, Verso, London-New York, 1999. Hay traducción castellana: Warren Montag, Cuerpos, masas, poder. Spinoza y sus contemporáneos, Madrid, Tierradenadie ediciones, 2005.

${ }^{41}$ Henri Meschonnic, Spinoza poema del pensamiento, Buenos Aires, Cactus, 2015, p. 300. Meschonnic analiza en concreto este pasaje de la carta 12 y considera que el sentido de ser como existir podría ser un hebraísmo. Para ello recurre a Sylvain Zac y a Maimónides: «Sylvain Zac , a propósito de Éxodo (III, 14), ehie/acher ehie dice: "el verbo Ehieh deriva del verbo Hayah que significa en hebreo, al menos según Maimónides, a la vez ser y existir"». Op. cit., p. 301. Meschonnic, que estudia el latín de Spinoza en cuanto escritura de su pensamiento, plantea dos paradojas fundamentales: la 
En este caso concreto del texto, ¿por qué fuerza el latín el filósofo? Nada más y menos que para unir ser y existir y dotar de un fuerte componente activo al ser. Lo que hace es retorcer el sentido escolástico de esencia para que emerja el núcleo fundamental de su ontología: la potencia activa de la existencia de la substancia infinita. Y ahí reside la apuesta clara y fuerte de la filosofía de Spinoza: en eso consiste el mayor gozo, existir, ser: la infinita fruitio existendi, esendi.

$\mathrm{Si}$ los diversos deleites que vivimos mientras avanzamos en los conocimientos racionales nos permiten escapar a veces a la tiranía del tiempo, es en esa crucial experiencia afectiva e intelectiva donde la duración parece quedar suspendida y donde el ser humano que ha desarrollado más su potencia, se ha perfeccionado más, puede atisbar que su mente es en su mayor parte eterna (E 5P39) ${ }^{42}$. Cuanto más logremos ocupar nuestra mente con ese modo activo de sentir y conocer, más libres seremos respecto a los afectos pasivos y

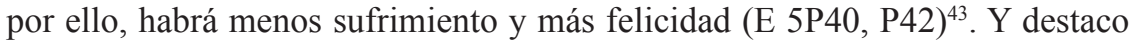
por mi parte ambas expresiones en cursiva por sus connotaciones espaciales. Es más, la vía liberadora que él nos propone consiste en esa visión de eternidad, en ese bien verdadero y comunicable que invocaba en sus inicios filosóficos. Pero esa eternidad no se explica como una defensa de la inmortalidad tradicional de las religiones, sino como una experiencia inmanente y espacial que certifica la persistencia del conatus en su línea expansiva, y que se vive como amplitud de espacios de felicidad en los que saltamos por encima de la sucesión temporal atada indefectiblemente a la imaginación y a la fluctuación afectiva. ¿Acaso para acceder a esos territorios gozosos es necesario saltar por encima de la duración sin que por ello deje de estar presente? Es obvio, ya que la perspectiva exclusiva de la duración nos devuelve una y otra vez a nuestra vulnerabilidad y mortalidad. De ahí que en numerosas ocasiones se haya vinculado la eternidad spinoziana con la presencia intemporal, atmosférica y lumínica de las figuras humanas y sus entornos cotidianos en los cuadros de Vermeer, con esa geometría eterna e íntima de su pintura ${ }^{44}$. ¿Quién mejor que un pintor que dominaba y trascendía el espacio gracias a su paleta cromática y a sus efectos ópticos para trasladar a través de la materia el sentimiento de eternidad que irradian las esencias singulares? ${ }^{45}$

primera la acabamos de ver en este ejemplo, el uso forzado del latín; la segunda, es que Spinoza, que pensaba y escribía su pensamiento en latín, "veía el hebreo como la lengua que gramaticalizaba su pensamiento" (p. 301). Meschonnic se hace eco del libro de Geneviève Brykman, La judéité de Spinoza, cuando se habla de un retorno del latín al hebreo a través del Compendio de gramática de la lengua hebrea, y la importancia que otorga Spinoza al nombre. Meschonnic llega a decir: "Spinoza encuentra, en el hebreo, el principio de claridad y de unidad que piensa y elabora en latín" (p. 303).

${ }^{42}$ Spinoza, Ética, op. cit., p. 411 (SO 2, 304).

${ }^{43}$ Ibidem, pp. 413-414, 416-417 (SO 2, 306-308).

${ }^{44}$ En mi libro Baruch Spinoza. Una nueva ética para la liberación humana, Madrid, Biblioteca Nueva, 2015, y en uno de sus capítulos, trato ampliamente la relación de la filosofía de Spinoza con la pintura holandesa, en concreto, con Vermeer y también con Rembrandt (pp. 119-133).

${ }^{45}$ La bibliografía al respecto es harto numerosa. Recordemos solo algunos títulos: Filippo Mignini, 
La intuición spinoziana descubrió ese lugar atemporal paradójico y a él volvía en sus meditaciones. Por eso, la felicidad no puede ser meramente durativa, no puede ser sucesiva ni continua (aunque él aspirara en su juventud a que esa experiencia fuera continua), sino que es la dimensión expansiva de nuestro ser, un salto discontinuo, cuántico, en medio del tejido temporal, un espacio de libertad, en suma. ¿Factible? Spinoza afirma en la última proposición de la Ética que, a pese a la dificultad, sí es posible alcanzar esta felicidad, este auténtico contento de sí (E 5P42)

Por todo ello, no es de extrañar que a veces se haya caracterizado la filosofía de este autor como demasiado abstracta. Por ejemplo, Schelling, quien sentencia de fatalismo - pero no de panteísmo- al spinozismo, ya que lo considera excesivamente abstracto, rígido y falto de vida, cual figura misteriosa por estar inacabada ${ }^{47}$.

Sin embargo, Spinoza no tenía como objetivo la reflexión melancólica sobre el fondo oscuro de la existencia, el sufrimiento, los estragos del devenir, la falibilidad y la muerte, sino que apostó fuerte por el gozo intelectual y la vida; él buscaba la expansión de la felicidad, persistir y resistir en ella a brazo partido. Y esto solo es posible desde una elevación del nivel de potencia cognoscitiva que nos hace más conscientes del doble plano en el que vivimos de modo sincrónico (la duración y la eternidad), y nos aporta la mayor alegría y serenidad.

Y Spinoza mismo define la eternidad de la siguiente manera al comienzo de la Ética: "Por eternidad entiendo la existencia misma, en cuanto se la concibe como siguiéndose necesariamente de la sola definición de una cosa eterna" ${ }^{\text {"48 }}$. Y en la explicación abunda el filósofo en que esa existencia se entiende como una verdad eterna que manifiesta la esencia de la cosa y que no puede explicarse por la duración o el tiempo, aunque se concibiese la duración como indefinida o sin principio ni fin. Y sigue acotando lo que es y que no la eternidad en su relación con la duración y el tiempo en la misteriosa proposición 23 del Libro Quinto de la Ética, ya que la eternidad no puede definirse por el tiempo, ni

Ars imaginandi. Apparenza e rappresentazione in Spinoza, Nápoles, Edizione Scientifiche Italiane, 1981; Pontus Hulten, Vermeer et Spinoza, París, L'Échoppe, 2002; Daniel Arasse, L'ambition de Vermeer, París, Adam Biro, 1993; Roberto Diodato, Vermeer, Góngora, Spinoza. L'estetica come scienza intuitiva, Milán, Bruno Mondadori, 1997; Norbert Schneider, Vermeer 1632-1675. Sentimientos furtivos, Köln, Taschen, 1994; Sara Hörnak, Spinoza und Vermeer. Immanenz in Philosophie und Malerei, Würzburg, Königshausen \& Neumann, 2004; Carlos Gurméndez, Amanecer en Holanda, Ferrol, Ensaio, 2000; Jean-Clet Martin, Bréviaire de l'éternité. Vermeer et Spinoza, Clamecy, Éditions Léo Scheer, 2011.

${ }^{46}$ Spinoza, Ética, op. cit., p. 417 (SO 2, 308).

${ }^{47}$ Schelling, op. cit., pp. 143-145: “...porque el sistema de Spinoza se parece mucho más a una obra de la que sólo se ha bosquejado el contorno exterior y de la que sólo se podrían advertir los muchos rasgos ausentes o inacabados una vez animada. Más bien habría que compararlo con las antiguas imágenes de los dioses, que parecían tanto más misteriosas cuantos menos rasgos individuales y vivos expresaban".

${ }^{48}$ Cf. Spinoza, Ética, op. cit., E 1def.8, p. 69 (SO 2, 46).

Araucaria. Revista Iberoamericana de Filosofía, Política, Humanidades y Relaciones Internacionales, año $21, \mathrm{n}^{\circ} 41$ Primer semestre de 2019. Pp. 117-138. ISSN 1575-6823 e-ISSN 2340-2199 doi: 10.12795/araucaria.2019.i41.06 
tiene relación con él, aunque sintamos y experimentamos que somos eternos ( $\mathrm{E}$ $5 \mathrm{P} 23 \mathrm{~S})^{49}$, de ahí que tenga mucho más ver con la vinculación entre el concepto $\mathrm{y}$ el afecto $^{50}$. La mente humana siente y experimenta en ella la dimensión de eternidad de la substancia infinita, y la siente desde siempre de modo natural aunque sólo desde la firmeza (firmitas) -también natural- cognoscitiva y ética pueda acceder a ella, ser plenamente consciente e integrarla en el hacer de la vida a través de una potenciación activa de ideas adecuadas.

Sabemos que articular este doble plano, durativo y eterno, en la coherencia del sistema inmanente de Spinoza es uno de los aspectos más problemáticos y misteriosos de la Ética. Numerosos intérpretes se ha aprestado a dilucidarlo. No es momento ahora de entrar en estas disquisiciones ${ }^{51}$. Por mi parte sostengo la hipótesis que ya formulé en su día acerca de una "sabiduría de la inmanencia" que permita conjugar eternidad y duración, a la vez que vivir su tensión inevitable:

La mente humana siente la eternidad, pero no se disuelve en un sentimiento oceánico de flotación en el mar de la substancia infinita, porque la mente humana además comprende y accede al tercer género de conocimiento o, más

${ }^{49}$ Ibídem, p. 399 (SO 2, 296).

${ }^{50}$ Cf. Pierre Meschonnic, op. cit., pp. 332-338.

${ }^{51}$ Por citar solo algunos títulos destacados y con interpretaciones diversas: Pierre-François Moreau, Spinoza. L'expérience et l'éternité, París, PUF, 1994; Chantal Jaquet, Sub specie aeternitatis. Étude des concepts de temps, durée et éternité chez Spinoza, París, Kimé, 1997; Vittorio Morfino, El tiempo de la multitud, Madrid, Tierradenadie Ediciones, 2014. Moreau en su libro ya de referencia obligada considera que la eternidad es un aspecto de la necesidad, es la plenitud afirmativa de la existencia, y el sentimiento de finitud constituye la condición del sentimiento de eternidad, e incluso es ese sentimiento, articulando la ordenación coherente entre razón y experiencia. Según las aportaciones de Chantal Jaquet, la eternidad no sería un simple punto de vista, o un género, o una especie, o una categoría, sino una propiedad real de la existencia necesaria; e incluso contrariando a Moreau, para Jaquet no es la finitud la que nos conduce a experimentar la eternidad, sino que es la certeza la que expresa ese sentimiento de lo eterno; y ello es debido a que la certeza implica la autoconciencia que, en virtud de sus diferentes grados, nos proporciona la sabiduría. Morfino, en su interpretación más reciente, defiende la teoría de la pluralidad de los tiempos. Para este autor la eternidad no es el resultado de la suma de las duraciones, ni una duración indefinida ni su contracción en un eterno presente, nunc stans o tota simul (p. 46), sino que es el principio de objetividad de la relación; la eternidad es lo sincrónico, no es el punto de indistinción de los tiempos, sino la lógica de su articulación (p. 49). Insiste además Morfino en que la Ética no es una obra en que importe lo serial, sino el orden y conexión de las ideas (la connexio como textura lucreciana o trenzar) (p. 27). "Lo sincrónico de lo que habla Althusser es el conocimiento de este entramado no reducible a una interioridad simple, es el conocimiento de Dios a través de las cosas singulares, como recita la proposición en la que Goethe leía el corazón y el secreto del spinozismo" (p. 48). Alude a una carta de Goethe a Jacobi donde concede una gran importancia al conocimiento de la ciencia intuitiva y decide consagrar a él su vida entera, sin preocuparse por sus límites. Y afirma Morfino: "El concepto de connexio nos empuja a un pensamiento más radical, a concebir las duraciones como efectos de encuentros de ritmos al infinito: esto significa que, a partir del conocimiento de una duración existente, nosotros podemos acceder a la de las duraciones existentes en relación con aquélla (que están asociadas con ella), sea bajo la forma abstracta e inadecuada del tiempo, que absolutiza un ritmo particular haciendo la mezcla de todos los demás, sea bajo la forma de la eternidad, concibiendo de manera adecuada la constitución relacional del tiempo en cuanto conexión compleja de duraciones y tomando adecuada distancia de todo intento de anclaje metafísico del tiempo a la totalidad" (pp. 46-47).

Araucaria. Revista Iberoamericana de Filosofia, Política, Humanidades y Relaciones Internacionales, año $21, \mathrm{n}^{\circ} 41$. Primer semestre de 2019. Pp. 117-138. ISSN 1575-6823 e-ISSN 2340-2199 doi: 10.12795/araucaria.2019.i41.06 
exactamente, integra con mayor grado de conciencia ese conocer que siempre ha estado a su alcance. Y aquí hay dos niveles en juego que no conviene solapar: por un lado, la eternidad es el substrato ontológico que posibilita el conocimiento adecuado y solamente desde esa dimensión es posible avanzar hacia la ciencia intuitiva; pero por otro lado y en el plano experiencial, es el acceso a esa visión cada vez más amplia y siempre presente en el proceso afectivo-cognoscitivo, desde el conocimiento racional al intuitivo, el que nos abre las puertas de la eternidad. A la comprensión sincrónica de esos dos niveles cual dos caras de la misma moneda es a lo que denomino 'sabiduría de la inmanencia' en Spinoza, y aquello a lo que me refiero cuando formulo la hipótesis acerca de un nuevo estado de evolución futura de la conciencia humana que puede ser anticipado desde esta novedosa interpretación de la Ética ${ }^{52}$.

Quizás la aporía pueda disolverse, o no, desde la propia vida y las transiciones conscientes y vibrantes que experimenta el intelecto humano en su trayecto de avance en medio del espacio de la susbtancia infinita, con los afectos removidos, las intuiciones logradas sobre ese lugar de apertura ilimitada al que sentimos como felicidad. Y es Spinoza mismo quien -en otra de sus cartas de gran interés para conocer su perfil psicológico, y utilizando de nuevo categorías espaciales expansivas- nos explica y certifica su perseverancia en el sosiego y la alegría, que le permite seguir avanzando y ascendiendo en el conatus natural de su esencia y alejarse de las tristezas:

\begin{abstract}
Y si acaso descubriera que el fruto, que ya he extraído del entendimiento natural, era falso, al menos una vez, eso me haría dichoso. Porque yo gozo y procuro pasar la vida no sumido en la tristeza y el llanto, sino con tranquilidad, alegría y jovialidad, y así asciendo un grado más. Al mismo tiempo reconozco (y ello me proporciona suma satisfacción y tranquilidad de espíritu) que todas las cosas son hechas por el poder del ser perfectísimo y por su inmutable decreto ${ }^{53}$.
\end{abstract}

Y otra vez, en la misma carta a Blijenbergh, Spinoza insiste en que el más alto grado de felicidad o beatitud consiste en el amor y el conocimiento de Dios, y que a ello procura dedicar todos sus actos y evitar lo que contraría su naturaleza singular ${ }^{54}$. Y prosigue más adelante en su correspondencia:

¿Acaso, me pregunto, vacía de contenido toda religión aquel que afirma que hay que reconocer a Dios como el sumo bien y que hay que amarlo, como tal, con libertad de espíritu; que en esto consiste nuestra suma felicidad y nuestra suma libertad; que, además, el premio de la virtud es la virtud misma y que el

\footnotetext{
${ }^{52}$ Pilar Benito Olalla, Baruch Spinoza. Una nueva ética para la liberación humana, 2015, op. cit., p. 541.

${ }_{53}$ Spinoza, Correspondencia, op. cit., Ep. 21, p. 193 (SO 4, 127). Carta a Blijenbergh, Schiedam, 28 de enero de 1665.

${ }^{54}$ Ibídem, p. 199 (SO 4, 131).
} 
castigo de la necedad y de la impotencia es la misma necedad; y, finalmente, que cada uno debe amar a su prójimo y obedecer los mandatos de la suprema autoridad $?^{55}$.

Esta insistencia por parte de Spinoza en la alegría, en la concentración del conocimiento sub specie aeternitatis, en el amor que exige y a la vez irradia este estado intuitivo de máxima comprensión, se debe a que él mismo sabe porque lo ha sentido y verificado- que es el arma más potente para disolver las pesadumbres y realizar nuestra esencia mediante la acción adecuada. Ese es el camino de la felicidad para una filosofía inmanente de la potencia constitutiva de los modos finitos, frente a los repliegues y recovecos del consuelo prometido por una trascendencia religiosa que nos achica y nos agita entre miedos y esperas.

El recorrido de Spinoza a través del conocimiento y en busca de la liberación no implica una verticalidad trascendente de caídas y elevaciones, sino una expansión multidimensional e inevitable del conatus, pero que además nunca es definitiva. Y quizás es esto lo que hizo y hace tan atractivo, incluso invulnerable, el sistema de Spinoza para muchos, a la vez que se constituye en fuente de rechazo para otros tantos. Alguien que se atreve a decir que entiende la verdadera filosofí ${ }^{56}$ es alguien que ha experimentado una felicidad verdadera, aunque no presuma que sea la mejor.

\section{Conclusiones}

Y a modo de conclusiones, más bien aproximaciones, en una cuestión tan compleja, experiencial y abierta como esta que nos ocupa, establezco las siguientes.

El gozo intelectual es una experiencia real y constituye el motor del conocimiento. Lo caracteriza el diálogo y la apertura al mundo, a los demás y a uno mismo. Además de ser un estado que no se consuma en él como tal, sino que actúa como elemento motivador necesario para comunicar y enseñar lo descubierto a los otros. Este aspecto interindividual lo dota de una fuerte potencia que crece en proporción geométrica. El afecto de alegría, nota distintiva de este estado, es similar en todas aquellas personas que lo sienten. En Spinoza también fue así. Sin embargo, lo que añade la peculiaridad al gozo intelectual spinoziano es que todos los gozos parciales se asentaban en un gozo mayor, la beatitudo de la ciencia intuitiva y el amor intelectual de Dios que

${ }^{55}$ Ibídem, p. 287 (SO 4, 220). Ep. 43: Carta a Jacob Ostens con ocasión del libelo de Lambert van Velthuysen sobre el TTP (Tratado teológico-político). La Haya, febrero de 1671.

${ }^{56} \mathrm{Ibidem}$, p. 397 (SO 4, 320): "Pues yo no presumo de haber hallado la mejor filosofía, sino que sé que entiendo la verdadera”. Ep. 76: Carta a Albert Burgh.

Araucaria. Revista Iberoamericana de Filosofia, Politica, Humanidades y Relaciones Internacionales, año $21, \mathrm{n}^{\circ} 41$. Primer semestre de 2019. Pp. 117-138. ISSN 1575-6823 e-ISSN 2340-2199 doi: 10.12795/araucaria.2019.i41.06 
implica la visión de eternidad. Y para comprender esta beatitud o felicidad son más sugestivas y cercanas las categorías espaciales (more geometrico), empáticas y de transparencia óptica, mientras que las categorías temporales (more arithmetico), solipsistas y de opacidad casan mejor con la tristeza y la melancolía. La paradoja entre la pesadumbre de mortalidad y la alegría de crecer y seguir vivo que genera tantas transiciones en nosotros, solo se puede abordar desde un aumento de la potencia propia y ajena, si queremos que la breve duración de una vida humana fructifique en un logro real.

Así que Spinoza en su peculiar manera de modo finito cognoscente e irrepetible fue feliz, y en cuanto nódulo del entramado universal de la substancia atisbó una eternidad que también nos contagia felicidad a nosotros cuando conseguimos entender el orden de su método, sentir sus consecuencias, y saltar y expandirnos por encima del continuo desgaste temporal, aunque sea brevemente. 


\section{Referencias bibliográficas:}

Aristóteles, Metafísica. Edición de Valentín García Yebra. Madrid, Gredos, 1982.

—, El hombre de genio y la melancolía. Prólogo y notas de Jackie Pigeaud. Traducción de Cristina Serna. Barcelona, Acantilado, 2016.

Benito, P., Baruch Spinoza. Una nueva ética para la liberación humana, Madrid, Biblioteca Nueva, 2015.

—, "La potencia humana del amor transformada en el amor intelectual de Dios" en María Luisa de la Cámara y Julián Carvajal (eds.): Spinoza y la Antropología en la Modernidad, Hildesheim, Georg Olms Verlag, 2017.

Bordelois, I., Etimología de las pasiones, Buenos Aires, Libros del zorzal, 2017.

Henry, M., La felicidad de Spinoza, Buenos Aires, Ediciones La Cebra, 2008 [ed. original: 2004].

Hörnak, S., Spinoza und Vermeer. Immanenz in Philosophie und Malerei, Würzburg, Königshausen \& Neumann, 2004.

Hulten, P., Vermeer et Spinoza, París, L’Échoppe, 2002.

Jaquet, Ch., Sub specie aeternitatis. Étude des concepts de temps, durée et éternité chez Spinoza, París, Kimé, 1997.

Klibansky, R., Panofsky, E., Saxl, F., Saturno y la melancolia, Madrid, Alianza Forma, 2006.

Kristeva, K., Sol negro. Depresión y melancolía. Traducción de Mariela Sánchez Urdaneta. Terrados (Girona), Wunderkammer, 2017.

Martin, J-C., Bréviaire de l'éternité. Vermeer et Spinoza, Clamecy, Éditions Léo Scheer, 2011.

Meschonnic, H., Spinoza poema del pensamiento, Buenos Aires, Cactus, 2015. Moreau, P-F., Spinoza. L'expérience et l'éternité, París, PUF, 1994.

Morfino, V., El tiempo de la multitud, Madrid, Tierradenadie Ediciones, 2014. Pigeaud, J., La maladie de l'âme: Étude sur la relation de l'âme et du corps dans la tradition médico-philosophique antique, París, Belles Lettres, 2006.

—, Melancholia: le malaise de l'individu, París, Payot et Rivages, 2008.

Schelling, F. W. J., Investigaciones filosóficas sobre la esencia de la libertad humana y los objetos con ella relacionados. Traducción de Helena Cortés y Arturo Leyte. Barcelona, Anthropos, 2000.

Schopenhauer, A., Aforismos sobre el arte de saber vivir. Traducción de Luis Fernando Moreno Claros. Madrid, Valdemar, 2012

Spinoza, B., Spinoza Opera. Edición de Carl Gebhardt, 4 vols, Heidelberg, C. Winter, 1972 [1ª ed.: 1925]. 
—, Correspondencia. Traducción de Atilano Domínguez. Madrid, Alianza, 1988.

-, Tratado de la reforma del entendimiento. Principios de filosofía de Descartes. Pensamientos metafísicos. Traducción de Atilano Domínguez. Madrid, Alianza, 1988.

-, Compendio de gramática de la lengua hebrea. Traducción de Guadalupe González Diéguez. Madrid, Trotta, 2005.

-, Ética demostrada según el orden geométrico. Traducción de Vidal Peña García, Madrid, Tecnos, 2007.

Steiner, G., Diez (posibles) razones para la tristeza del pensamiento. Traducción de María Condor. Madrid, Siruela, 2007.

Wagensberg, J., El gozo intelectual. Teoría y practica sobre la inteligibilidad y la belleza, Barcelona, Tusquets Editores, 2007. 